\title{
Factitious disorder imposed on another: a diagnostic dilemma
}

\author{
Zaburzenie pozorowane narzucone innym - trudności diagnostyczne
}

\author{
Abhineetha Hosthota', Swapna Bondade², K.A. Prithvi Raj' \\ 'Department of Dermatology, the Oxford Medical College Hospital and Research Centre, Bangalore, India \\ 2Department of Psychiatry, the Oxford Medical College Hospital and Research Centre, Bangalore, India \\ Dermatol Rev/Przegl Dermatol 2020, 107, 484-486 \\ DOI: https://doi.org/l0.5 | |4/dr.2020.101679
}

Here we discuss a case of factitious disorder imposed on another (FDIA).

An 18-year-old girl was brought to the dermatology department by her mother with a history of recurrent ulcers over the legs which healed on conservative management since childhood. On examination, ulcers were multiple, well defined, angulated, superficial with oozing, hyperpigmented borders (fig. 1). There were multiple hyperpigmented and atrophic scars on the legs. We suspected epidermolysis bullosa, cutaneous vasculitis and pyoderma gangrenosum. Routine investigations were normal. Skin biopsy showed nonspecific histopathological findings. Staphylococcus aureus was grown on culture. She was treated with antibiotics and occlusive dressings and did not develop any fresh lesions in these 20 days (fig. 2). She came with fresh lesions after a week, at an easily accessible area with similar morphology suggestive of self-inflicted injuries. This raised a suspicion of factitious disorder.

On the psychiatrist's evaluation, the patient had depressive symptoms with a Hamilton Depression score of 16, suggesting mild to moderate depression. International personality disorder examination (IPDE) suggested emotionally unstable personality disorder (EUPD)-borderline type personality. She was started on fluoxetine $20 \mathrm{mg}$ and amitriptyline $25 \mathrm{mg}$ for depression. In the ward, nursing staff observed the mother inflicting injuries with a twig and worsening of ulcers, which raised the suspicion of FDIA.

FDIA is a form of abuse where an individual deliberately produces or feigns clinical illness in a person under his or her care. It is also known as Munchausen syndrome by proxy, coined by Meadow in 1977 [1]. Predisposing factors are psychiatric illness, medical history with repeated hospitalization, and resentment against health professionals. Among 9\%, it mimics acute or chronic skin disease, leading to misdiagnosis [2].
W pracy przedstawiamy przypadek zaburzenia pozorowanego narzuconego drugiej osobie (factitious disorder imposed on another - FDIA).

Do oddziału dermatologicznego zgłosiła się matka z osiemnastoletnią córką. Powodem zgłoszenia były owrzodzenia kończyn dolnych występujące u córki, które nawracały od dzieciństwa i goiły się pod wpływem leczenia. W badaniu stwierdzono obecność licznych owrzodzeń o wyraźnych granicach i nieregularnym kształcie, powierzchownych, o sączących, przebarwionych brzegach (ryc. 1). Na kończynach dolnych wykazano także liczne przebarwione blizny zanikowe. Podejrzewaliśmy pęcherzowe oddzielanie się naskórka, zapalenie naczyń lub piodermię zgorzelinową. W rutynowych badaniach nie stwierdzono odchyleń od stanu prawidłowego. W badaniach histopatologicznych materiału biopsyjnego uzyskano nieswoiste wyniki. W posiewie wyhodowano gronkowca złocistego (Staphylococcus aureus). Wdrożono leczenie z zastosowaniem antybiotyków i opatrunków okluzyjnych. Przez 20 dni nie pojawiły się żadne nowe zmiany (ryc. 2). Po tygodniu pacjentka zgłosiła się ze świeżymi zmianami o podobnej morfologii, w łatwo dostępnym miejscu, co wskazywało, że mają one charakter samookaleczeń. Powzięto wówczas podejrzenie zaburzeń pozorowanych.

W ocenie psychiatrycznej stwierdzono objawy depresyjne. Wynik 16 punktów w skali depresji Hamiltona odpowiadał depresji o nasileniu łagodnym do umiarkowanego. Wynik oceny osobowości według International Personality Disorder Examination (IPDE) wskazał na występowanie u pacjentki osobowości chwiejnej emocjonalnie typu granicznego (borderline). Włączono leczenie przeciwdepresyjne fluoksetyną w dawce $20 \mathrm{mg}$ i amitryptyliną w dawce $25 \mathrm{mg}$. Podczas pobytu pacjentki na oddziale personel pielegniarski zaobserwował, jak matka zadaje córce rany przy użyciu gałązki, co powoduje pogorszenie stanu owrzodzeń. Obserwacje te naprowadziły na rozpoznanie FDIA. 


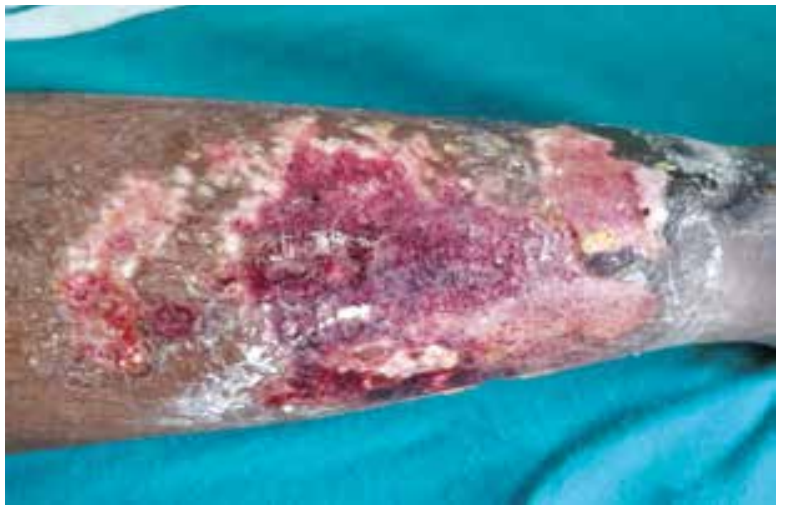

Figure I. Ulcer

Rycina I. Owrzodzenie

The victim revealed an uneventful childhood, denied the mother's role in causing the ulcers and cooperated with management. The devastating effects of FDIA are behavioural issues, post-traumatic stress disorder, suicidal ideation, anxiety, depression, and low self-esteem with a $9-12 \%$ mortality rate due to complications $[2,3]$. Our patient had depression with borderline type of EUPD. Perpetrators are described as intelligent, articulate and medically sophisticated. They invariably have mental illness or history of factitious disorder [3]. The initial source of the ulcer could not be elicited but direct observation of harm and abatement of symptoms in absence of the perpetrator were the evidence for our diagnosis.

Perpetrator interview revealed family dysfunction and lack of social outlets after spouse demise. Saad proposed the dark side of parental investment theory, where motherly instincts are subverted by narcissistic attributes and increased need for attention [4]. After confrontation, the mother accepted the act but her intention was not revealed. Perpetrators behaviours after confrontation are: temporary cessation, intensified efforts, rage, denial and acceptance. Psychiatrists play a vital role in convincing the perpetrator to undergo psychotherapy. Victims may require conservative treatment with separation from the perpetrator.

In our case, the dominant mother and passive daughter combination could be a possibility in falsification acts. There are very few reports of FDIA with an adult proxy. We assume that FDIA is underdiagnosed due to lack of clinician's awareness, the manipulative nature of the perpetrator, the victim not regarding abuse as harm or both collaborating to deceive the clinician. It requires heightened awareness and a multidisciplinary approach among clinicians, social workers and legal authorities.

\section{CONFLICT OF INTEREST}

The authors declare no conflict of interest.

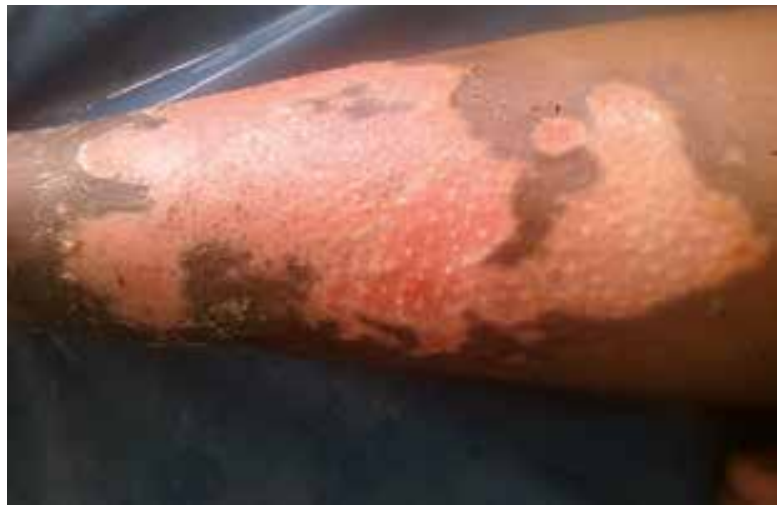

Figure 2. Healing ulcer

Rycina 2. Gojące się owrzodzenie

W FDIA sprawca celowo wywołuje albo pozoruje schorzenie kliniczne u osoby znajdującej się pod jego opieką. Zaburzenie pozorowane narzucone innym jest również znane jako zastępczy (przeniesiony) zespół Münchhausena. Termin ten wprowadził do piśmiennictwa medycznego Meadow w 1977 r. [1]. Czynniki predysponujące do rozwoju tego zaburzenia obejmują chorobę psychiczną, częste hospitalizacje w wywiadzie medycznym, a także uraz w stosunku do pracowników ochrony zdrowia. W 9\% przypadków objawy przypominają ostrą lub przewlekłą chorobę skóry, co prowadzi do błędnego rozpoznania [2].

Pacjentka oświadczyła, że jej dzieciństwo przebiegało bez problemów. Zaprzeczyła, aby matka miała jakikolwiek udział w wywoływaniu owrzodzeń. Współpracowała z lekarzami w czasie terapii. FDIA wywołuje u ofiar traumatyczne skutki w postaci zaburzeń behawioralnych, zespołu stresu pourazowego, myśli samobójczych, stanów lękowych, depresji i obniżonej samooceny. W 9-12\% przypadków następuje zgon ofiary wskutek powikłań $[2,3]$. U przedstawionej pacjentki stwierdzono depresję oraz osobowość chwiejną emocjonalnie typu granicznego. Sprawcy FDIA są opisywani jako osoby inteligentne, elokwentne i posiadające sporą wiedzę medyczną. Mają zaburzenie psychiczne lub mają zaburzenie pozorowane w wywiadzie [3]. W opisanym przypadku początkowo nie udało się ustalić przyczyny owrzodzeń, jednak ostatecznie rozpoznanie ustalono na podstawie zaobserwowanej bezpośrednio czynności zadawania ofierze ran, a także ustępowania objawów pod nieobecność sprawczyni.

Wywiad przeprowadzony u matki ujawnił zaburzone relacje rodzinne oraz brak życia towarzyskiego po śmierci małżonka. Saad twierdzi, że zastępczy (przeniesiony) zespół Münchhausena może mieć związek z instynktami macierzyńskimi, w których dominują cechy narcystyczne i wzmożona potrzeba uwagi u matki [4]. W przedstawionym przypadku po przeprowadzeniu konfrontacji matka przyznała się do czynu, ale nie ujawniła swoich motywów. Zazwyczaj po konfrontacji u sprawców występują następujące reakcje: czasowe wstrzymanie dzia- 
łań, wzmożenie zachowań, gniew, zaprzeczenie i akceptacja. Istotną rolę w skłonieniu sprawców do podjęcia psychoterapii odgrywają psychiatrzy. Natomiast ofiary mogą wymagać leczenia zachowawczego oraz oddzielenia od sprawcy.

W prezentowanym przypadku za pozorowanie choroby może odpowiadać połączenie dominującej matki i biernej córki. W piśmiennictwie istnieje niewiele doniesień opisujących przypadki zaburzenia pozorowanego narzuconego osobie dorosłej. Przypuszczamy, że część przypadków FDIA jest nierozpoznana z powodu braku świadomości lekarzy oraz dużej zdolności manipulowania otoczeniem u sprawców. Należy też zaznaczyć, że ofiary nie uważają znęcania się za krzywdę, a zdarza się, że obie strony współpracują ze sobą w celu wprowadzenia lekarzy w błąd. Postępowanie w przypadku FDIA wymaga wzmożonej czujności i podejścia wielodyscyplinarnego z udziałem klinicystów, pracowników socjalnych i organów ścigania.

\section{KONFLIKT INTERESÓW}

Autorzy nie zgłaszają konfliktu interesów.

\section{References}

\section{Piśmiennictwo}

1. Filho D.S., Kanomata E.Y., Feldman R.J., Neto A.M.: A Munchausen syndrome and Munchausen syndrome by proxy: a narrative review. Einstein 2017, 15, 516-521.

2. Boyd A.S., Ritchie C., Likhari S.: Munchausen syndrome and Munchausen syndrome by proxy in dermatology. J Am Acad Dermatol 2014, 71, 376-381.

3. Narang T., Kanwar A.J., Kumaran M.S., Singh S.M.: Munchausen by proxy in a family. Indian J Dermatol Venereol Leprol $2012,78,748-750$

4. Saad G.: Munchausen by proxy: the dark side of parental investment theory? Med Hypotheses 2010, 75, 479-481.

Received: 13.04 .2020

Accepted: 14.08.2020

Otrzymano: 13.04.2020 r.

Zaakceptowano: $14.08 .2020 \mathrm{r}$.

How to cite this article

Hosthota A., Bondade S., Prithvi Raj K.A.: Factitious disorder imposed on another: a diagnostic dilemma. Dermatol Rev/

Przegl Dermatol 2020, 107, 484-486. DOI: https:/ / doi.org/10.5114/dr.2020.101679. 